\title{
Science and Applications of Low-Emittance Electron Beams
}

\author{
K. van Bibber
}

August 20, 2000

U.S. Department of Energy

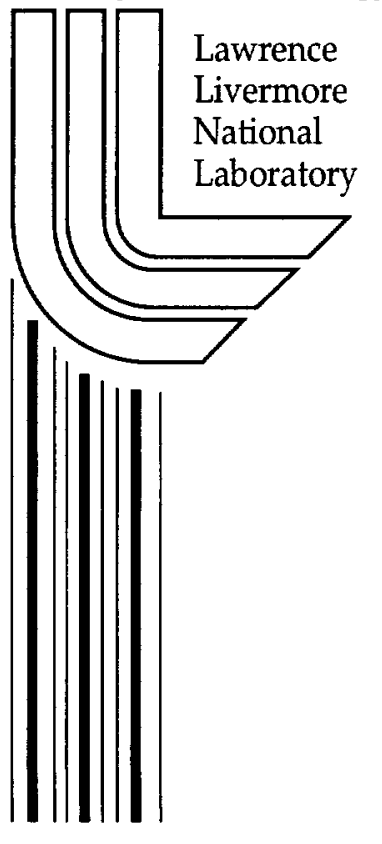




\section{DISCLAIMER}

This document was prepared as an account of work sponsored by an agency of the United States Government. Neither the United States Government nor the University of California nor any of their employees, makes any warranty, express or implied, or assumes any legal liability or responsibility for the accuracy, completeness, or usefulness of any information, apparatus, product, or process disclosed, or represents that its use would not infringe privately owned rights. Reference herein to any specific commercial product, process, or service by trade name, trademark, manufacturer, or otherwise, does not necessarily constitute or imply its endorsement, recommendation, or favoring by the United States Government or the University of California. The views and opinions of authors expressed herein do not necessarily state or reflect those of the United States Government or the University of California, and shall not be used for advertising or product endorsement purposes.

This work was performed under the auspices of the U. S. Department of Energy by the University of California, Lawrence Livermore National Laboratory under Contract No. W-7405-Eng-48.

This report has been reproduced directly from the best available copy.

Available electronically at http://www.doc.gov/bridge

Available for a processing fee to U.S. Department of Energy

And its contractors in paper from

U.S. Department of Energy

Office of Scientific and Technical Information

P.O. Box 62

Oak Ridge, TN 37831-0062

Telephone: (865) 576-8401

Facsimile: (865) 576-5728

E-mail: reports@adonis.osti.gov

Available for the sale to the public from

U.S. Department of Commerce

National Technical Information Service

5285 Port Royal Road

Springfield, VA 22161

Telephone: (800) 553-6847

Facsimile: (703) 605-6900

E-mail: orders@ntis.fedworld.gov

Online ordering: http://www.ntis.gov/ordering.htm

\section{OR}

Lawrence Livermore National Laboratory

Technical Information Department's Digital Library

http://www.llnl.gov/tid/Library.html 
Final Report for the FY99 LDRD Project

(Exploratory Research in the Disciplines)

\title{
Science and Applications of Low-Emittance Electron Beams \\ (99-ERD-055)
}

\author{
Karl van Bibber, P.I. \\ N-Division/Physics \& Advanced Technology Directorate \\ August 20, 2000
}

\section{Introduction.}

The capability of making very low-emittance electron beams of temporally short, high charge bunches has opened up exciting new possibilities in basic and applied science. Two notable applications are high energy electron-positron linear colliders for particle physics, and fourthgeneration light sources consisting of linac-driven Free-Electron Lasers (FEL), both of which represent significant programmatic potential for the Laboratory in the future. The technologies contributing to low-emittance electron beams and their applications, namely precision fabrication, ultra-short pulse lasers, and RF photocathode injectors, are all areas of Lab expertise, and the work carried out under this LDRD project further expanded our core-competency in advanced concept accelerators. Furthermore, high energy accelerators have become a cornerstone of the SBSS program, as illustrated by the recent development of proton radiography as a prime technology candidate for the Advanced Hydrotest Facility (AHF), which enhanced the significance of this project all the more.

This was a one-year project to both advance the technology of, and participate in the science enabled by very low-emittance electron beams. The work centered around the two themes above, namely electron-positron linear colliders, and the new fourth-generation light sources. This work built upon previous LDRD investments, and was intended to emphasize accelerator physics experiments.

\section{Description of work carried out and most significant results.}

Below we describe our accomplishments within this LDRD project, and provide the context for these results. The detailed technical descriptions are mostly found in the attached UCRL reports. The usual channel for disseminating the most timely and exciting results in accelerator physics is the Particle Accelerator Conference (PAC) held in North America every two years, and the European Particle Accelerator Conference (EPAC) held in the intervening years. Five of the six attached reports are from the PAC'99 Proceedings and reflect work accomplished or culminating in the performance period of this LDRD award. The other report is a long and authoritative paper currently under review by a relatively new refereed electronic journal "Physical Review Special Topics Accelerators and Beams".

\section{A. Accelerator technology for linear colliders.}

There is currently keen interest around the world in the possibility of building a TeV-scale electronpositron linear collider for precision studies of physics beyond the Standard Model. It is almost certain that either the Fermilab collider upgrade, or the European Large Hadron Collider (LHC) will 
see the first evidence for new physics in proton collisions over the next few years, but detailed highstatistics studies can only be accomplished with a high-luminosity $\mathrm{e}^{+} \mathrm{e}^{-}$linear collider. There is both a US-Japan study of an X-band room-temperature concept [1], and a German S-band superconducting concept, and there is optimism that either or both will become real projects sometime early this decade. In both cases, the reduction of the electron beam phase space is accomplished by synchrotron damping rings at low energy $(\sim \mathrm{GeV})$, but the principal challenge is maintaining the extremely low beam emittance over the $10 \mathrm{~km}$ of acceleration in the main linac. Exquisite care in accelerator physics design is required, but equally important is precision fabrication and assembly of a large number of nearly identical parts constituting the structure. This is particularly so for the Xband structure, with critical feature sizes ranging from 1-10 $\mathrm{mm}$ scale, and dimensional and alignment tolerances on the order of 1-10 microns (see Figure 2 of Ref. [2], and Figure 2 of Ref. [4]).

- Completion of X-band structure DDS-3. In FY97-99, LLNL in conjunction with SLAC and KEK, the Japanese High Energy Accelerator Research Organization made and tested a joint venture prototype $1.8 \mathrm{~m} \mathrm{X}$-band accelerator structure. Our Lab developed the process for the precision machining of 206 similar but non-identical acclerator cells, and manufactured them. KEK developed the process for vacuum diffusion-bonding them into a monolithic structure, and bonded the actual structure successfully. SLAC, who provided the electromagnetic design, brazed all the couplers and manifolds onto the structure, and set up the completed assembly for beam testing. The overall discussion of the evolution of the Detuned (DT) and Damped-Detuned Structures (DDS), culminating in the construction of DDS-3, is described in Ref. [2]. The specific details on the development of procedures for precision machining and metrology of the X-band cells is found in Ref. [3].

- Bonding and Brazing studies for copper structures. Our principal work during the performance period of this LDRD project was a comprehensive study of diffusion bonding and brazing of copper cells for normal-conducting linear collider structures. This study represented a systematic study of all variables in joining cells into structures which critically affect performance - good vacuum properties, electromagnetic integrity and tolerances. These variables include machining surface preparation, brazing vs. diffusion bonding, brazing material, loading of the cells, and the temperature and time of the furnace process. This work is under review by a major electronic journal for accelerator physics [4].

- ASSET wakefield test. The ASSET facility on the main SLAC linac is a test-bed for characterizing the wakefields of accelerator structures. A pair of electron bunches with variable separation in time are accelerated down the SLAC linac and directed into the ASSET line. The 'leader' bunch is deliberately steered off-axis in position in angle to induce wakefields in the structure, and the resulting kick given to the trailing 'witness' pulse measures the effect of the wakes (Figure 1). A complete data-set of the transverse deflections of the witness bunch, as a function of leader trajectory and their time separation, fully characterizes the structure wakefields (Figure 2). There was an unexpected finding in this work of potentially significant benefit to linear colliders. Namely, as the power removed by each of the 4 damping manifolds depends sensitively on offset of the beam from the acceleration axis, and as the frequency of the transverse (damped) mode is unique to each cell, from the frequency spectrum of each damping manifold one can uniquely derive the position of the beam at each position within the accelerator structure. The trajectory of the beam in DDS-3 measured from the ASSET test reflects the deviations of the structure from perfect straightness, and they agree at the micron level with those from a coordinate measuring machine of the structure on the bench (Figure 3). Use of the damping manifolds to determine 
beam position may obviate the need for and the space allocated to dedicated beam-position monitors in the design of a linear collider.

- Related work. As a result of our collaboration with SLAC on R\&D for the Next Linear Collider, we became involved in helping solve how bunches of positrons may be created with the required intensity and low emittance. For the world's first linear collider, the Stanford Linear Collider (SLC), positrons were created by crashing a $30 \mathrm{GeV}$ electron beam on a thick rotating cooled tungsten-rhenium target and capturing and accelerating the shower of positrons which emerge from the back of the target. The challenge is that the SLC target failed during its last run, showing significant beam-related damage, and the NLC target will need to handle an order of magnitude greater power. Specifically, we applied Laboratory expertise in thermohydraulic and thermal shock modeling to do a retrospective study of the SLC target failure, and guide the development of the future NLC target. We also connected SLAC with the group at LANL which has been doing the hot-cell materials analysis of the SLC target. This work continues beyond the performance period of the LDRD; a preliminary discussion of the results is found in Refs. [5,6].

\section{B. Technologies for Fourth-Generation Light Sources.}

Within the past decade, theoretical work by Prof. Claudio Pellegrini of UCLA has laid the groundwork for operation of FELs in an entirely new regime, Self-Amplified Spontaneous Emission (SASE). An electron bunch of suitably high charge and small emittance is produced and accelerated to high energy in a linac, and injected into a long precision-fabricated undulator. Starting from noise, the electron bunch will self-modulate, resulting in maximally bunched sheets of charge. At this point, the FEL exponential gain curve saturates. LLNL has been involved in a collaboration with SLAC, UCLA, and LANL (and more recently FNAL) in a study of the possibility of such a 'fourthgeneration' light source, called the Linac Coherent Light Source (LCLS), that would utilize the last third of the SLAC 2-mile linac to accelerate electrons from an RF photocathode gun to $15 \mathrm{GeV}$, and a $100 \mathrm{~m}$ long permanent-magnet undulator. The predicted brightness at $8 \mathrm{keV}-10^{33}$ photons $\cdot \mathrm{sec}^{-}$ $1 \cdot \mathrm{mm}^{-2} \cdot \mathrm{mr}^{-2} \cdot(0.1 \% \mathrm{BW})^{-1}-$ is 10 orders of magnitude greater than from any existing 'third generation' light source, such as the Argonne APS. The radiation is diffraction limited and fully transverse coherent. The scientific applications of such radiation are extraordinarily rich, including single-shot holography of biomolecules, femtosecond pulse-probe measurements, and exploration of non-linear QED phenomena. The report of the Birgeneau-Shen committee empaneled by the Office of Basic Energy Sciences gave highest priority towards fourth-generation light source R\&D, and an internationally-constituted Director's Review at SLAC (11/97) found no technical fault with our preliminary design report [7]. Subsequently, a subpanel of the Basic Energy Sciences Advisory Committee (BESAC), the "Leone Panel" (2/99) did an extensive study of the opportunities and technologies for 4th-generation and other novel radiation sources, and gave its highest priority to the development of an X-ray FEL. Nevertheless, while a real project may get underway early next decade, there is much basic science and technology development to carry out in the meantime.

While there is full confidence in the theory and modeling, it is important to valide SASE physics in the IR and optical before extrapolating to the x-ray regime. The original LCLS institutions above, plus BNL have entered into a collaboration to perform an experiment called VISA ('VIsible SAse'), at the Accelerator Test Facility (ATF), a well-characterized $70 \mathrm{MeV}$ electron linac at Brookhaven. This should produce gain saturation in a FEL in the optical regime $(<1 \mu)$. LLNL performed the engineering and design of the $4 \mathrm{~m}$ undulator and its vacuum vessel (Figure 4), which was fabricated at SLAC and is now installed at the ATF (Figure 5). 
We also have designed and fabricated a FROG autocorrelator (Frequency Resolved Optical Gating), a key diagnostic for measuring the output pulse, and tested it using the FALCON laser in B194. The LLNL FROG is part of the suite of sophisticated diagnostics that will be required to understand the performance of the VISA FEL [8].

It was our hope that the lasing of VISA would occur during the performance period of the LDRD project. Difficulties in installation and alignment slowed progress, however, and 'first light' only occurred in FY00. Commissioning is proceeding slowly as the remaining problems understanding the undulator magnetic field map and the measured electron trajectory are being worked out.

This work was performed under the auspices of the U.S. Department of Energy by Lawrence Livermore National Laboratory under Contract No.W-7405-Eng-48.

\section{References.}

1. "The Zeroeth-Order Design Report for the Next Linear Collider", May, 1996 (LBNL-PUB5424, SLAC Report 474, UCRL-ID-124161).

2. “Accelerator Structure R\&D for Linear Colliders", J.W. Wang et al., Proc. of the 1999 Particle Accelerator Congerence, 3423, New York, 1999 (UCRL-JC-136456).*

3. "Fabrication of DDS-3, and 11.4 GHz Damped-Detuned Structure", J. Klingmann et al., Proc. of the 1999 Particle Accelerator Congerence, 777, New York, 1999 (UCRL-JC-13351).*

4. "Diffusion Bonding and Brazing of High Purity Copper for Linear Collider Accelerator Structures", J.W. Elmer, J. Klingmann and K. van Bibber (UCRL-JC-135547, Rev. 2); submitted to Physical Review Special Topics - Accelerators and Beams (PRST-AB).*

5. "The NLC Injector System", V. Bharadwaj et al., Proc. of the 1999 Particle Accelerator Congerence, 3447, New York, 1999 (UCRL-JC-136450)**

6. "Recent Developments in the Design of the NLC Positron Source", T. Kotseroglou et al., Proc. of the 1999 Particle Accelerator Congerence, 3450, New York, 1999 (UCRL-JC-136449).*

7. "Linac Coherent Light Source (LCLS) Design Report”, April, 1998.

8. "Photon Beam Diagnostics for the VISA FEL", A. Murokh et al., Proc. of the 1999 Particle Accelerator Congerence, 2480, New York, 1999 (UCRL-JC-136457).*

* Reprints attached constituting part of this Final Report. 


\section{Figures.}

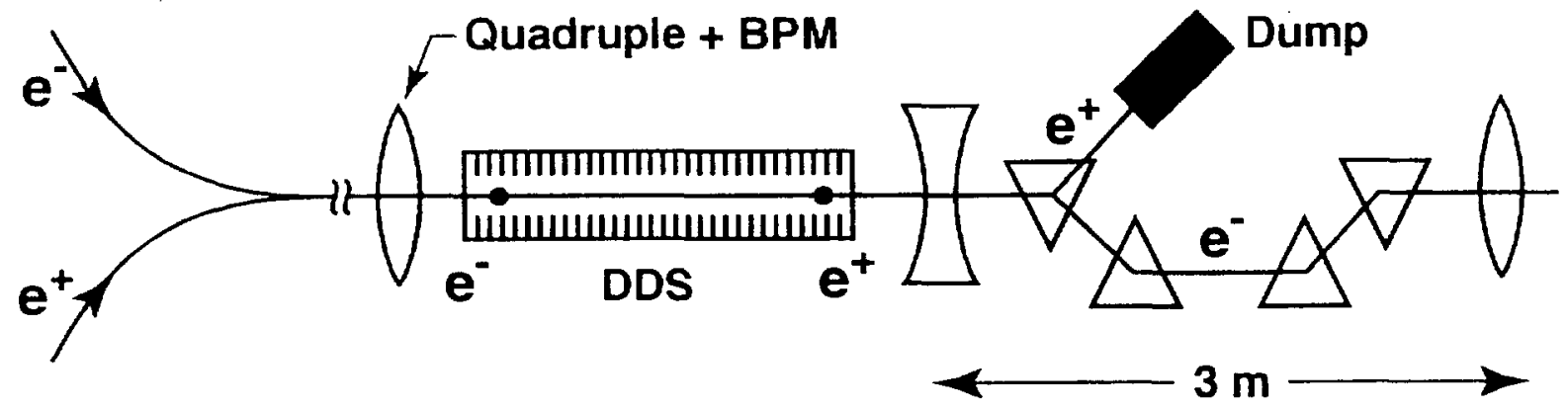

Figure 1. Schematic of the ASSET test facility at the SLAC linac. The first ('leader') bunch through the structure is launched deliberately off-axis either in position and/or angle, to induce wakefields in the structure. The second ('witness') bunch follows at a variable time delay from the first, and the phase and magnitude of the wakefield is measured by the kick to it, as measured in a downstream spectrometer.

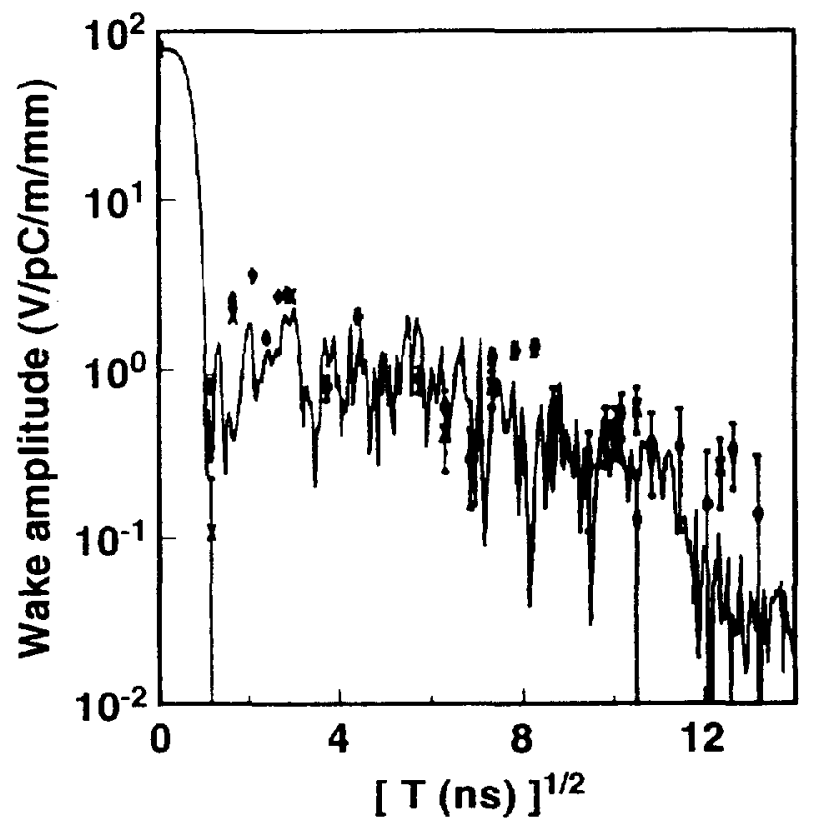

Figure 2. Wakefields measured for DDS-3 at the ASSET facility. The agreement with the theory is generally good, but deviations occur both at short and long times. The origin of these deviations is known to originate from one group of 38 cells, for whom the irises of the accelerating cavities were known to have had a systematic deviation of $\sim 10$ microns from their design values. 


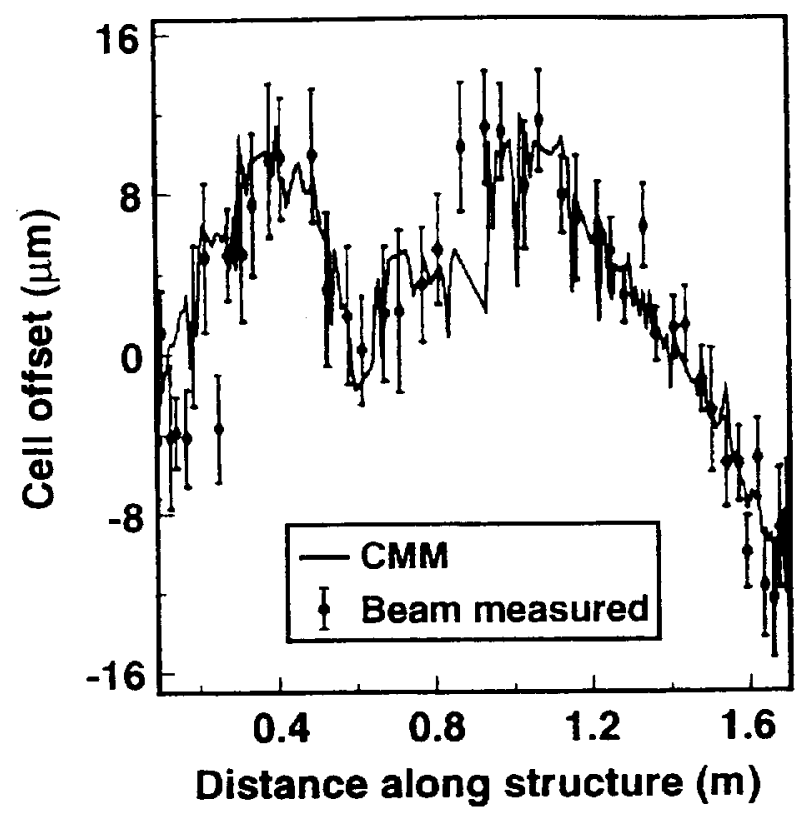

Figure 3. Deviations from straightness of the DDS-3 structure, determined both by the apparent beam offset in the ASSET test, and from a coordinate measuring machine. The agreement between the two methods is at the micron-level.
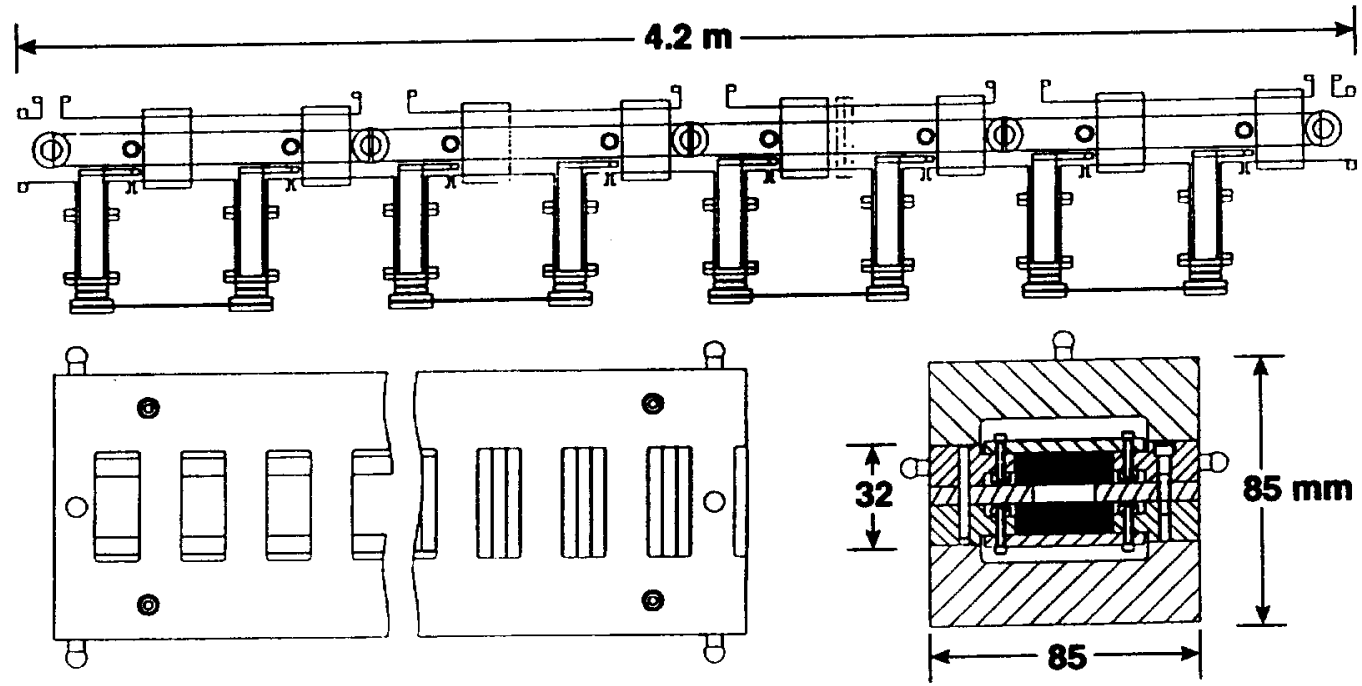

Figure 4. Assembly drawing of the VISA undulator and vacuum vessel designed by LLNL. A principle milestone of the experiment will be to observe saturation of the gain curve for SASE radiation in an experiment at BNL. 


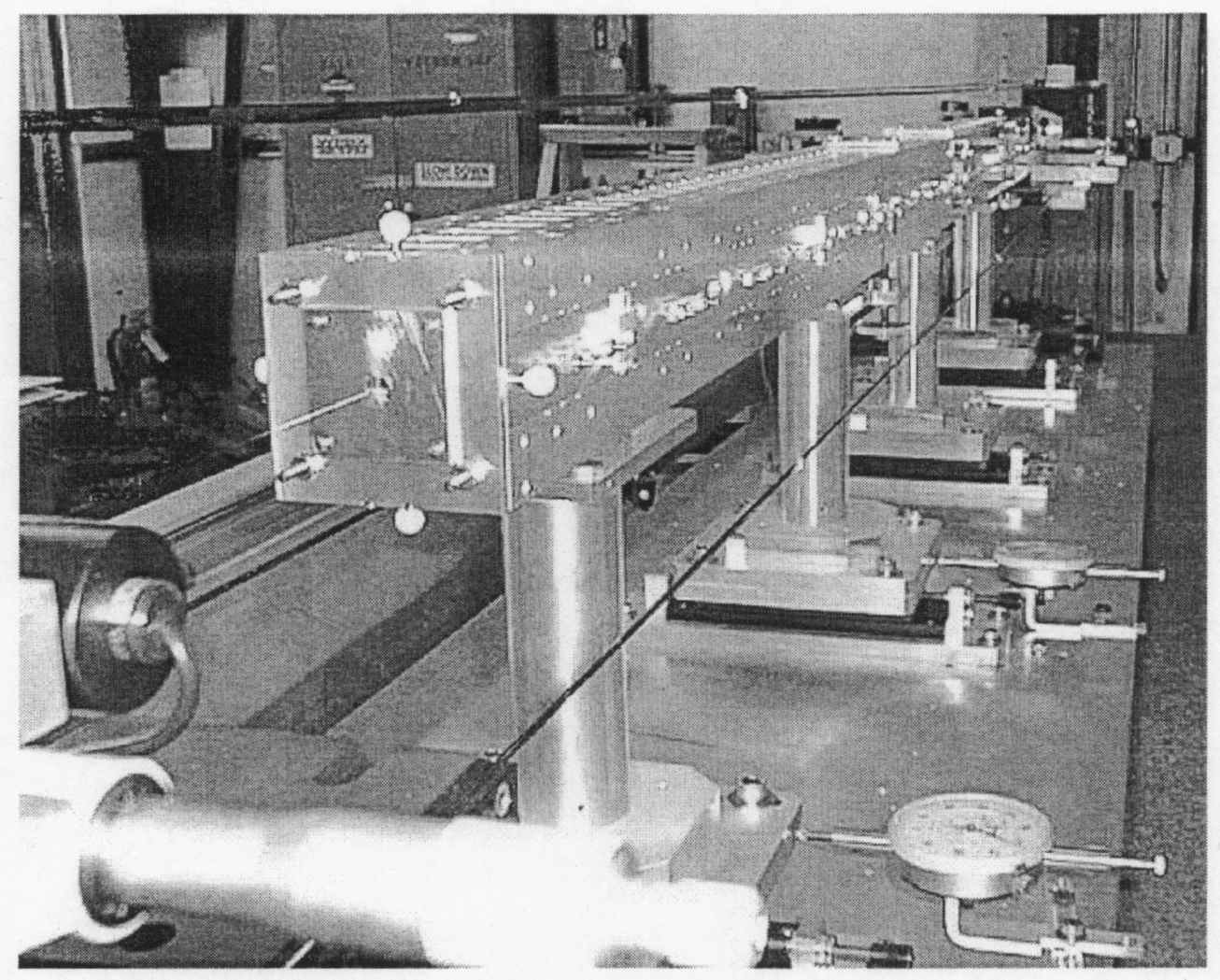

Figure 5. Photograph of the VISA undulator and vacuum vessel designed by LLNL, now on the beam line at Brookhaven National Laboratory's Accelerator Test Facility (ATF). 